\title{
Effect of Nobel Metal Ions on the Synthesis of Metal Nanoclusters for Selective Detection of Various Heavy Metals
}

\author{
Amit Nain ${ }^{1,2,3}$, Fan-Gang Tseng ${ }^{2} *$ and Huan-Tsung Chang ${ }^{3 *}$ \\ ${ }^{1}$ Taiwan International Graduate Program, Institute of Physics, Academia Sinica, Taipei 11529, \\ Taiwan \\ ${ }^{2}$ Department of Engineering and System Science, National Tsing Hua University, Hsinchu, 30013, \\ Taiwan \\ ${ }^{3}$ Department of Chemistry, National Taiwan University, Taipei 10617, Taiwan \\ ${ }^{*}$ Corresponding authors
}

Prof.F.-G.Tfangang@ess.nthu.edu.tw,

Prof. H.-T.C changht@ntu.edu.tw

\begin{abstract}
In this study, effect of noble metal ions $(\mathrm{Au}, \mathrm{Ag}$ and $\mathrm{Cu})$ on the synthesis of metal nanoclusters (MNCs) have been investigated. Through heating at $70^{\circ} \mathrm{C}$, TSA/BSA-Au, $-\mathrm{Ag}$ and $-\mathrm{Cu} \mathrm{NCs}$ were separately prepared from $\mathrm{Au}^{3+}, \mathrm{Ag}^{+}$and $\mathrm{Cu}^{2+}$ respectively in the presence of bovine serum albumin (BSA) and thiosalicylic acid (TSA). They exhibit photoluminescence (PL) at 700, 624 and $430 \mathrm{~nm}$, with an average life times of 1500, 100 and $11.71 \mathrm{~ns}$, respectively, when excited at $350 \mathrm{~nm}$. X-ray photoelectron spectroscopy (XPS) data support the presence of metal core $\left(\mathrm{M}^{0}\right)$ and metal-thiolate shell $\left(\mathrm{M}_{\mathrm{n}}-\mathrm{SR}_{\mathrm{m}}\right)$ in each of the TSA/BSA-Metal nanoclusters (MNCs). Spectroscopic measurements reveal the formation of $\mathrm{Au}_{32}-\mathrm{SR}, \mathrm{Ag}_{9}-\mathrm{SR}$ and $\left(\mathrm{Cu}_{4}-\mathrm{Cu}_{13}\right)-\mathrm{SR}$ species in the TSA/BSA-Au, $-\mathrm{Ag}$ and $-\mathrm{Cu}$ NCs respectively. Through PL quenching of the TSA/BSA-Au, $-\mathrm{Ag}$ and $-\mathrm{Cu} \mathrm{NCs}$, they have been used separately for quantitation of $\mathrm{Hg}^{2+}, \mathrm{As}^{3+}$ and $\mathrm{Cr}^{6+}$, with linear ranges of 1-400, 4-18, and 40-400 $\mathrm{nM}$ and limits of detection (LODs) of $0.25,2.34$ and $3.54 \mathrm{nM}$, respectively. The PL quenching is mainly due to aggregation of the MNCs via metal-metal or metal-thiol interaction. The stable TSA/BSA-Au, $-\mathrm{Ag}$ and $-\mathrm{Cu}$ NCs have been employed separately for the determination of the concentrations of $\mathrm{Hg}^{2+}, \mathrm{As}^{3+}$ and $\mathrm{Cr}^{6+}$ ions in the spiked sea water samples, showing advantages of simplicity, rapidity, high selectivity, and sensitivity.
\end{abstract}

Keywords: Metal nanoclusters, Thiosalicylic acid, BSA, Fluorescence, Heavy metal, sensors

\section{Introduction}

Mercury $\left(\mathrm{Hg}^{2+}\right)$, Arsenic $\left(\mathrm{As}^{3+}\right)$ and Hexavalent chromium $\left(\mathrm{Cr}^{6+}\right)$ are extremely toxic heavy metals and possess a devastating health risk to a living kind, hence causing the renal, respiratory and neural systems related disorders [1]. According to Environmental Protection Agency (EPA), the maximum permissible limit $\mathrm{Hg}^{2+}, \mathrm{As}^{3+}$ and $\mathrm{Cr}^{6+}$ in drinking water are 2, 10, and $100 \mathrm{ppb}$ respectively. Conventional analytical methods used to detect such heavy metals in drinking or environmental samples includes HPLC, AAS/AES, GC-MS, etc., however these techniques are time-consuming, expensive, requires a skilled personals, sophisticated instruments, and lack of field deployability.

In the past decade, colorimetric methods using carbon (e.g., graphene oxide, carbon dots) and metal (e.g., $\mathrm{Au}, \mathrm{Ag}, \mathrm{Cu}, \mathrm{Fe}$ ) based nanomaterials (size $\geq 10 \mathrm{~nm}$ ) functionalized with various labels (e.g., DNA, dye, protein, thiol ligands etc.) have been developed for detection of heavy metal ions [2]. Such visual inspection methods are high throughput, offered better sensitivity and selectivity, also enabled multichannel detection by modifying the labels. Nevertheless, label free methods with 
improved features including simplicity, speed, compatibility, sensitivity, and selectivity are highly demanding. Recently, photoluminescent MNCs decorated with biomolecules (protein, DNA, etc.,)/ligand (thiols, polymers etc.) have gained immense interest as sensing probes due of their fascinating core shell structure with extremely tiny size $(\sim 2 \mathrm{~nm})$, and large stokes shift [3].

PL quenching based sensing strategy interest scientific community because it is sensitive, rapid, simple, highly selective and have on-site applicability. Various types of MNCs have been reported to exhibit PL properties via quantum confinement effect, charge transfer complex properties, and their interaction with analytes results in the change in their PL intensity which enable them for metal ion detection [4]. However, the application of MNCs for heavy metal ion detection is a challenge due to the poor selectivity, arising from the similar metal-metal interaction of different metal ions with the MNCs and also complexation with the ligands. Therefore, to achieve high selectivity of the MNCs-based systems, additional strategies, such as pretreatment of the samples and masking agents are required. In our previous study, we reported the effect of TSA isomers on the optical properties of copper nanoclusters aggregates prepared in different solvents [5].

In this study, we investigated the effect of metal core on PL properties and interaction with heavy metal ions, when stabilized by bovine serum albumin (BSA) and TSA in the aqueous solution. We find ourselves inclined towards building a sensor array for the detection of toxic heavy metal ions using different metal core such as $\mathrm{Au}, \mathrm{Ag}$ and $\mathrm{Cu}$ with a same surface ligand, by simple procedure. We used a simple hydrothermal method to prepare $\mathrm{Au}, \mathrm{Ag}$ and $\mathrm{Cu}$ NCs from respective ions in a separate solution containing TSA and BSA to form TSA/BSA-Au, TSA/BSA-Ag and TSA/BSA$\mathrm{Cu}$ NCs with sub nanometer size and possess a strong interaction with $\mathrm{Hg}^{2+}, \mathrm{As}^{3+}$ and $\mathrm{Cr}^{6+}$, respectively. A facile, rapid, inexpensive, highly selective and sensitive technique for the detection of $\mathrm{Hg}^{2+}, \mathrm{As}^{3+}$ and $\mathrm{Cr}^{6+}$ in aqueous solution, based on metallophilic and metal-thiol complexation or inner filter effect induced PL quenching of MNCs have been developed. A schematic representation of the synthesis of BSA and TSA capped MNCs and the method of detection of heavy metal ions is presented in Figure 1. 


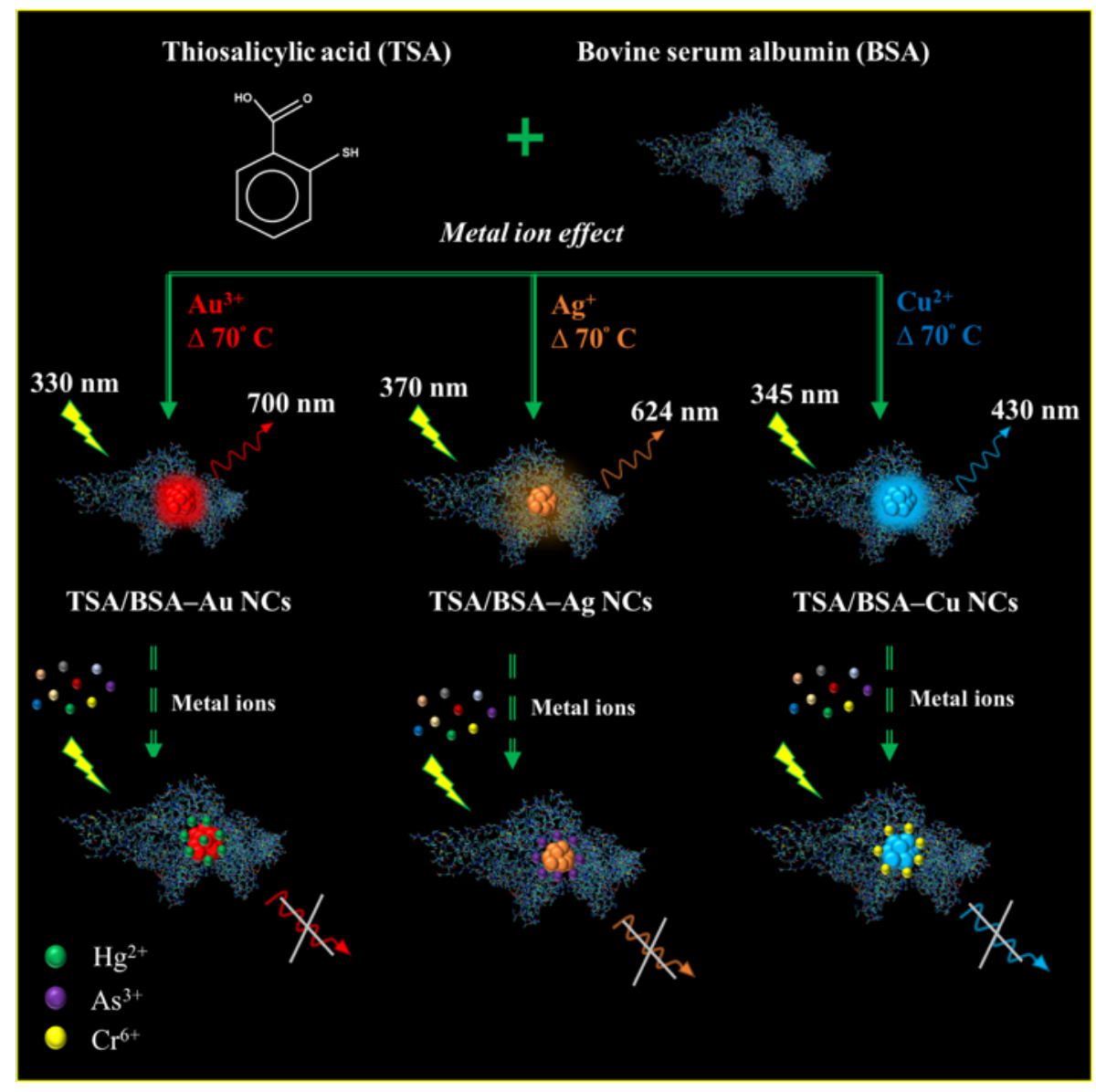

Figure 1 Schematic representation of noble metal ion effect on the synthesis of TSA/BSA stabilized MNCs. Equivalent concentration $(5 \mathrm{mM})$ of $\mathrm{Au}^{3+}, \mathrm{Ag}^{+}$and $\mathrm{Cu}^{2+}$ ions when incubated with BSA $(100 \mu \mathrm{M})$ and TSA $(10 \mathrm{mM})$ at $70^{\circ} \mathrm{C}$ results in the formation of tiny sized photoluminescent TSA/BSA-Au NCs (red), TSA/BSA-Ag NCs (orange), and TSA/BSA-Cu NCs (blue) and further demonstration of the selective interaction with $\mathrm{Hg}^{2+}, \mathrm{As}^{3+}$ and $\mathrm{Cr}^{6+}$ respectively. Digital photographs showing the real time solutions of MNCs under day light (left side) and UV-light (right side).

\section{Material and Methods}

Synthesis of TSA/BSA-Au, $\mathrm{Ag}$ and $\mathrm{Cu} N C s$

In a $1 \mathrm{~mL}$ vial $\mathrm{HAuCl}_{4}, \mathrm{AgNO}_{3}$ and $\mathrm{Cu}\left(\mathrm{NO}_{3}\right)_{2}(100 \mathrm{mM}, 50 \mu \mathrm{L})$ was added separately to the solution containing BSA $(6.64 \mathrm{mg} / \mathrm{mL})$, TSA $(10 \mathrm{mM})$ which were then subjected to heat at $70^{\circ} \mathrm{C}$. As prepared $\mathrm{Au}, \mathrm{Ag}$ and $\mathrm{Cu} \mathrm{NCs}$ were cooled down to room temperature, purified using a dialysis and stored at $4^{\circ} \mathrm{C}$ dark.

\section{Characterization}

UV-Vis absorption and PL spectra of TSA/BSA-Au, Ag and $\mathrm{Cu}$ NCs were recorded using a double beam UV-Vis spectrophotometer (Cintra 10e, GBC, Victoria, Australia) and Cary Eclipse Fluorescence spectrophotometer (Varian, Palo Alto, CA, USA), respectively. 


\section{Detection of heavy metals}

Sensing probes such as TSA/BSA-Au NCs $([\mathrm{Au}]=1000 \mathrm{nM})$ and TSA/BSA-Ag NCs $([\mathrm{Ag}]=100$ $\mathrm{nM})$ were mixed separately with the aliquots containing mixture of EDTA $(10 \mathrm{mM})$ and $\mathrm{Hg}^{2+}(0-$ $400 \mathrm{nM})$ and EDTA $(10 \mathrm{mM})$, TSA $(100 \mu \mathrm{M})$ and $\mathrm{As}^{3+}(0-20 \mathrm{nM})$ respectively dispersed in sodium phosphate buffer $(10 \mathrm{mM}, \mathrm{pH} 7.0)$ at room temperature for $10 \mathrm{~min}$. However, as prepared TSA/BSA-Cu NCs $([\mathrm{Cu}]=80 \mathrm{nM})$, were spiked into the solution containing $\mathrm{Cr}^{6+}(0-400 \mathrm{nM})$ in sodium phosphate buffer $(10 \mathrm{mM}, \mathrm{pH} 9.0)$ without any further treatment. Each of the solutions were then transferred individually into 96-well microtiter plates and their PL spectra were measured using a Synergy 4 microplate reader (BioTek, Winooski, VT, USA) at a fixed excitation wavelength of $350 \mathrm{~nm}$. Limit of detections (LOD) were determined using the following formulae:

$\mathrm{LOD}=\mathrm{c}^{*} \mathrm{SD} / \mathrm{m}$, where $\mathrm{c}$ is the signal to noise ratio, $\mathrm{SD}$ is the standard deviation of the blank and $\mathrm{m}$ is the slope of regression line.

\section{Results and Discussion}

\section{Characterization}

Figure 1 briefly describes the one-step synthesis approach used for the preparation of highly fluorescent, ultra-stable metal NCs. BSA actuates the nucleation and growth of metal NCs which are facilitated by the amino acids such as cysteine, histidine (coordination with metal ions) and tyrosine (assist in cluster formation) [5]. Figure 2 shows the absorption (2A), and emission (2B) spectra of TSA/BSA-Au, $-\mathrm{Ag}$, and $-\mathrm{Cu} \mathrm{NCs}$ respectively. UV-Vis absorption spectra of $\mathrm{TSA} / \mathrm{BSA}-\mathrm{Au},-\mathrm{Ag}$ and $-\mathrm{Cu} \mathrm{NCs}$ shows a small hump around $300 \mathrm{~nm}$ due to the presence of TSA/BSA-MNCs, whereas absence of characteristic peak around 500 to $600 \mathrm{~nm}$ confirms that solution is devoid of larger particles. TSA/BSA-Au, $-\mathrm{Ag}$ and $-\mathrm{Cu} \mathrm{NCs}$ emitted maximum PL intensity at 700 (bright red), 624 (orange) and 430 (blue) nm respectively upon excitation with 350 $\mathrm{nm}$. Such large stock shifts attributed to the coordination of $\mathrm{Au}^{+}$and $\mathrm{Ag}^{+}$with the surface groups of TSA and BSA inducing ligand-to-metal-metal charge transfer (LMMCT) and/or ligand-to-metal charge transfer (LMCT) [6].

(A)

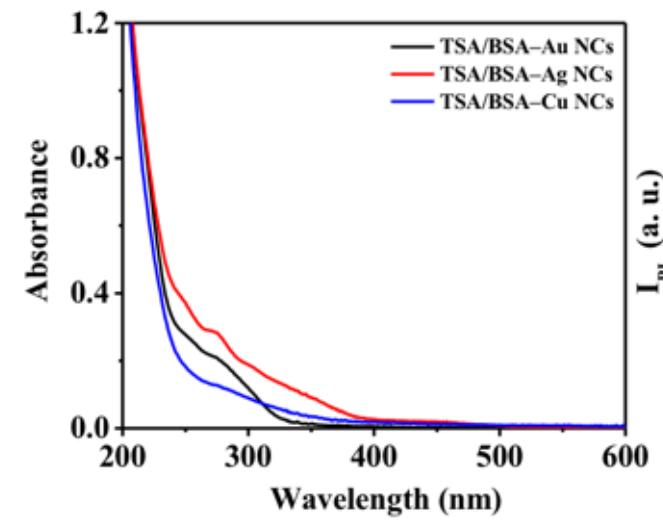

(B)

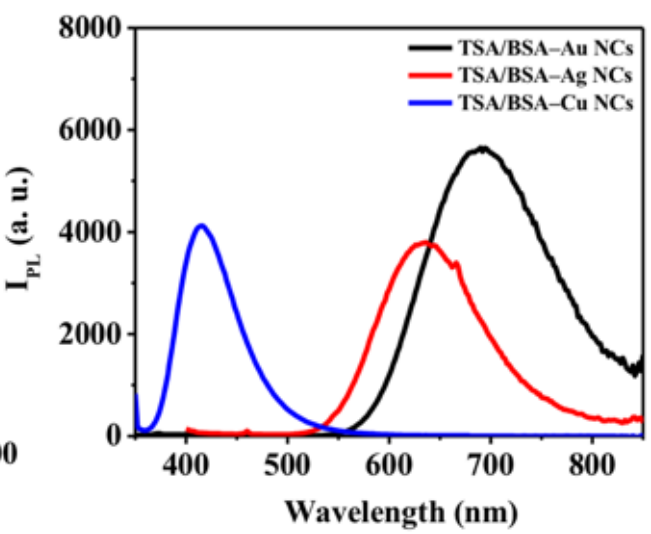

Figure 2 (A) UV-Vis absorption, and (B) PL emission spectra of TSA/BSA-Au, TSA/BSA-Ag and TSA/BSA-Cu NCs. Each solution was separately diluted 1000-fold with sodium phosphate buffer (10 mM, pH 7.4) for the absorption and PL measurements. 
Furthermore, our developed probe is stable for over 3 months when stored at $4^{\circ} \mathrm{C}$ dark (Figure $3 \mathrm{~A}$ ) and withstand high salt concentration i.e., upto $800 \mathrm{mM}$ (Figure 3B) and UV (330 nm) exposure upto $12 \mathrm{~h}$ (Figure 3C).
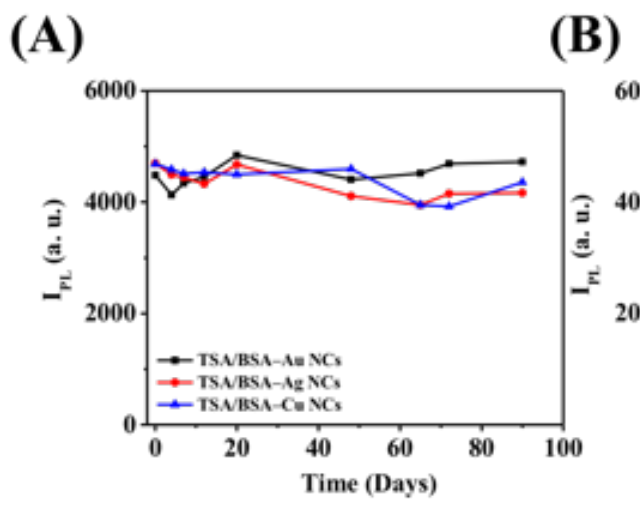

(C)

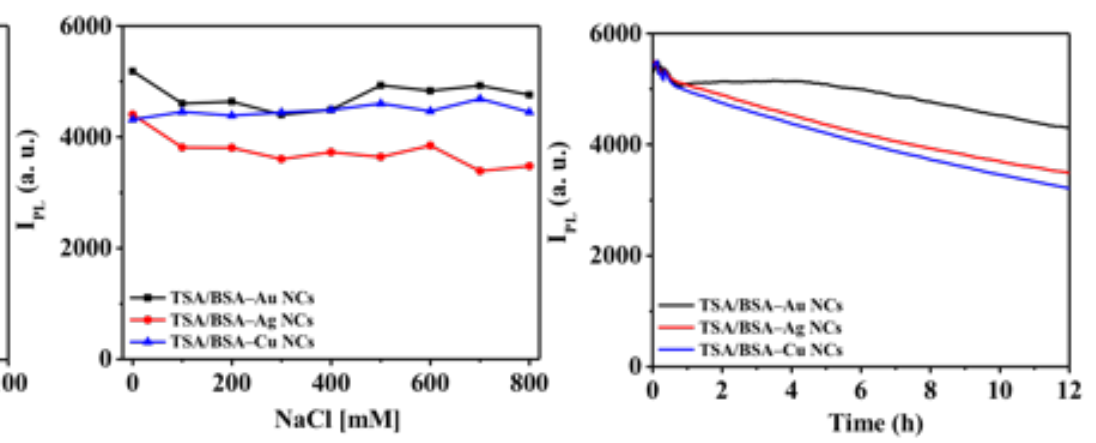

Figure 3 The stability of TSA/BSA-Au, TSA/BSA-Ag and TSA/BSA-Cu NCs. The PL intensity at 700,624 and $430 \mathrm{~nm}$ of as prepared photoluminescent TSA/BSA-Au, TSA/BSA-Ag and TSA/BSA-Cu NCs, respectively, (A) storage at $4{ }^{\circ} \mathrm{C}$, (B) $\mathrm{NaCl}(0-800 \mathrm{mM}),(\mathrm{C})$ photo-irradiation (UV-lamp, $365 \mathrm{~nm}$ ).

\section{Sensor performance}

PL responses of TSA/BSA-Au, $-\mathrm{Ag}$ and $-\mathrm{Cu} \mathrm{NCs}$ at 700,624 and $430 \mathrm{~nm}$, respectively, upon separate incubation with various metal ions $\left(\mathrm{Cd}^{2+}, \mathrm{Ni}^{2+}, \mathrm{Mg}^{2+}, \mathrm{Pb}^{2+}, \mathrm{Mn}^{2+}, \mathrm{Zn}^{2+}, \mathrm{Co}^{2+}, \mathrm{As}^{3+}, \mathrm{Cr}^{6+}\right.$, $\mathrm{Cu}^{2+}, \mathrm{Ag}^{+}, \mathrm{Fe}^{3+}$ and $\mathrm{Hg}^{2+}$ ion, $\left.100 \mu \mathrm{M}\right)$ in sodium phosphate buffer $(10 \mathrm{mM}, \mathrm{pH} 7.0)$ at room temperature for $10 \mathrm{~min}$ were studied. To circumvent the interference from the undesired metal ions and enable specific detection, EDTA $(10 \mathrm{mM})$ and TSA $(100 \mu \mathrm{M}) \&$ EDTA $(10 \mathrm{mM})$ were mixed with the TSA/BSA-Au, and -Ag NCs respectively prior to addition of $\mathrm{Hg}^{2+}$, and $\mathrm{As}^{3+}$, however TSA/BSA-Cu NCs were directly employed for $\mathrm{Cr}^{6+}$ detection (Figure 4(A-C)-i). The analytically significant PL quenching of TSA/BSA-Au, $-\mathrm{Ag}$ and $-\mathrm{Cu} \mathrm{NCs}$ by $\mathrm{Hg}^{2+}, \mathrm{As}^{3+}$ and $\mathrm{Cr}^{6+}$ ions, respectively, were determined by measuring the $\mathrm{PL}$ intensity ratio $\left(\mathrm{I}_{\mathrm{F} 0}-\mathrm{I}_{\mathrm{F}}\right) / \mathrm{I}_{\mathrm{F} 0}$, where $\mathrm{I}_{\mathrm{F} 0}$ and $\mathrm{I}_{\mathrm{F}}$ are the PL intensities (a. u) in the absence and presence of $\mathrm{Hg}^{2+}, \mathrm{As}^{3+}$ or $\mathrm{Cr}^{6+}$. PL intensity of TSA/BSA-Au, $-\mathrm{Ag}$ and $-\mathrm{Cu} \mathrm{NCs}$ were gradually decreased with an increase in $\mathrm{Hg}^{2+}, \mathrm{As}^{3+}$ and $\mathrm{Cr}^{6+}$ ions concentration respectively, resulting in a good linear relationship with the concentration of respective ions ranging from 1 to $400 \mathrm{nM}\left(R^{2}=0.9913\right), 4$ to $18 \mathrm{nM}\left(R^{2}=0.9897\right)$, and 40 to 400 $\mathrm{nM}\left(R^{2}=0.9905\right)$, respectively and Limit of detection (LOD) of $\mathrm{Hg}^{2+}, \mathrm{As}^{3+}$ and $\mathrm{Cr}^{6+}$ ions were found to be $0.25 \mathrm{nM}(0.068 \mathrm{ppb}), 2.34 \mathrm{nM}(0.463 \mathrm{ppb})$ and $3.54 \mathrm{nM}(1.04 \mathrm{ppb})$, respectively (Figure 4(A-C)-ii). 
(A)
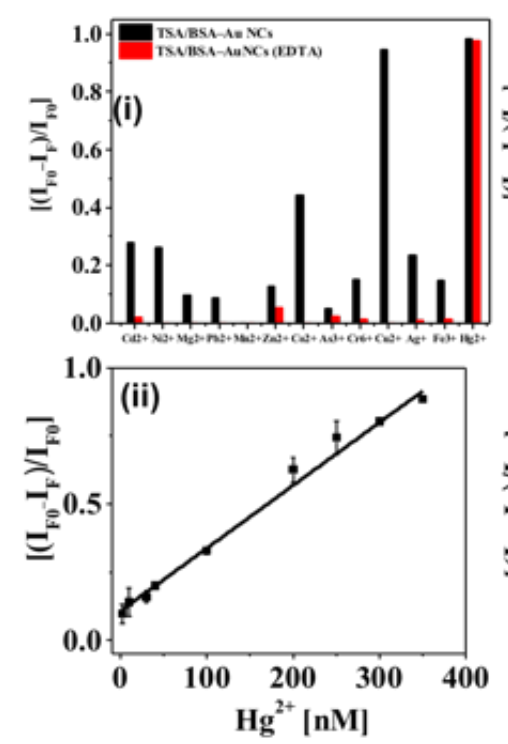

(B)

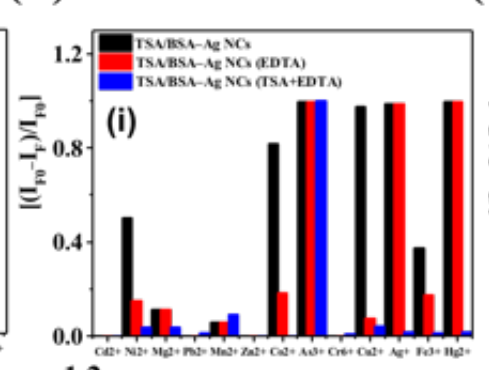

(C)

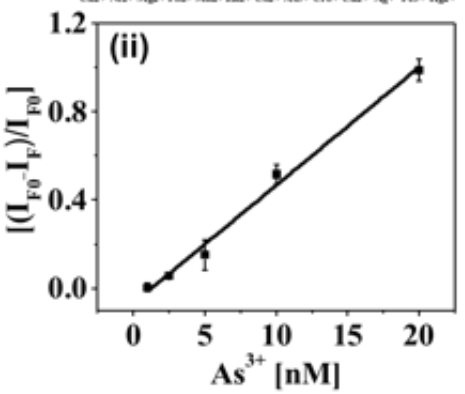

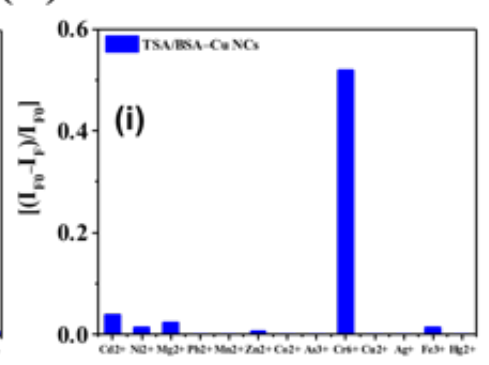

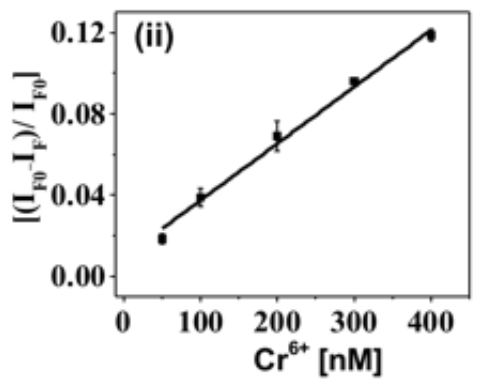

Figure $4 \mathrm{~A}-\mathrm{C}$ (i) $\mathrm{PL}$ ratios $\left[\left(\mathrm{I}_{\mathrm{F} 0}-\mathrm{I}_{\mathrm{F}}\right) / \mathrm{I}_{\mathrm{F} 0}\right]$ at 700,624 and $430 \mathrm{~nm}$ for TSA/BSA-Au, $-\mathrm{Ag}$ and $-\mathrm{Cu}$ $\mathrm{NCs}$, respectively, measured in the absence and presence of TSA $(100 \mu \mathrm{M})$ and EDTA $(1 \mathrm{mM})$ after the addition of $100 \mu \mathrm{M}$ metal ions in $5 \mathrm{mM}$ sodium phosphate buffer solution. Figure $4 \mathrm{~A}-\mathrm{C}$ (ii) shows the linear range of TSA/BSA-Au, $-\mathrm{Ag}$ and $-\mathrm{Cu}$ NCs upon addition of $\mathrm{Hg}^{2+}, \mathrm{As}^{3+}$ and $\mathrm{Cr}^{6+}$ respectively. 


\section{Conclusions}

The effect of noble metal ions ( $\mathrm{Au}, \mathrm{Ag}$ and $\mathrm{Cu}$ ) on the synthesis and optical properties of metal nanoclusters (MNCs) was studied. In conclusion a new, facile, rapid, and highly selective and sensitive technique for detection of $\mathrm{Hg}^{2+}, \mathrm{As}^{3+}$ and $\mathrm{Cr}^{6+}$ ions using TSA/BSA$\mathrm{Au},-\mathrm{Ag}$, and $-\mathrm{Cu} \mathrm{NCs}$, respectively, in aqueous media based on metallophilic and metalthiol interaction, and inner filter effect induced PL quenching have been developed. The TSA/BSA-Au and TSA/BSA-Ag NCs demonstrated remarkably high selectivity for $\mathrm{Hg}^{2+}$ and $\mathrm{As}^{3+}$ ions over other metal ions, in presence of masking agent EDTA and TSA-EDTA, respectively. However, TSA/BSA-Ag NCs exhibited intrinsic specificity toward $\mathrm{Cr}^{6+}$ without any pretreatment of the analytes or masking agent. The MNCs could detect as low as 0.25 , 2.34 and $3.54 \mathrm{nM}$ of $\mathrm{Hg}^{2+}, \mathrm{As}^{3+}$ and $\mathrm{Cr}^{6+}$ ions, respectively. This strategy primarily involved green chemistry approach and due to great aqueous solubility ( $>100$ days), photostability, salt tolerance (against $\mathrm{NaCl}$ up to $0.8 \mathrm{M}$ ) and therefore successfully employed for $\mathrm{Hg}^{2+}, \mathrm{As}^{3+}$ and $\mathrm{Cr}^{6+}$ ions detection in the sea water.

\section{Acknowledgement}

We are grateful to the Ministry of Science and Technology (MOST) of Taiwan for providing financial support for this study under contracts NSC 107-2113-M-002-015-MY3.

\section{References}

[1] Paul B Tchounwou, Clement G Yedjou, Anita K Patlolla, and Dwayne J Sutton, Heavy Metals Toxicity and the Environment,101, 7643-8340 (2012)

[2] Ming Li, Honglei Gou, Israa Al-Ogaidi, and Nianqiang Wu, Nanostructured sensors for detection of heavy metals: A review, ACS Sustainable Chem. Eng., 1, 713-723 (2014)

[3] Xun Yuan, Teik Jin Yeow, Qingbo Zhang, Jim Yang Lee and Jianping Xie, Highly luminescent Ag+ nanoclusters for Hg2+ ion detection, Nanoscale, 4, 1968-1971 (2012)

[4] Pekka Pyykkö, Theoretical chemistry of gold, Angew. Chem. Int. Ed., 43, 4412-4456 (2004)

[5] Yi-Jyun Lin, Po-Cheng Chen, Zhiqin Yuan, Jia-Ying Ma and Huan-Tsung Chang, The isomeric effect of mercaptobenzoic acids on the preparation and fluorescence properties of copper nanoclusters, Chem. Commun.,51, 11983-11986 (2015)

[6] Jianping Xie, Yuangang Zheng and Jackie Y. Ying, Protein-directed synthesis of highly fluorescent gold nanoclusters, J. Am. Chem. Soc., 3, 888-889 (2009) 